\title{
Resource utilization for acute lower gastrointestinal hemorrhage: The Ontario Gl Bleed Study
}

\author{
Dan Comay MD, John K Marshall MD MSc FRCPC
}

D Comay, JK Marshall. Resource utilization for acute lower gastrointestinal hemorrhage: The Ontario GI Bleed Study. Can J Gastroenterol 2002;16(10):677-682.

OBJECTIVES: Acute lower gastrointestinal hemorrhage (LGIH) is a common indication for hospitalization. However, there are few published studies of related health care resource utilization. Resource utilization, length of stay (LOS) and direct medical costs were characterized in a cohort of patients admitted for nonmalignant LGIH to centres in Ontario.

METHODS: Consecutive admissions for LGIH were identified at four Ontario hospitals. Profiles of resource utilization, LOS and estimates of direct medical costs were compiled through detailed chart review and adaptation of an administrative database. All centres were participants in the Ontario Case Cost Project. Linear regression models of log-transformed data were constructed to identify demographic variables predictive of LOS and case cost.

RESULTS: Among 124 patients enrolled (mean age 58.8 years) the average case cost was $\$ 4,832$ (SD $\$ 7,187$ ) for 7.5 days in hospital (SD 12.0). Diverticular disease was the bleeding source most often identified $(34.6 \%)$, followed by hemorrhoids (13.7\%) and ischemic colitis $(9.7 \%)$. Older age and comorbid illness, specifically coronary artery disease (CAD), were associated with both increased LOS and higher case cost in univariate regression analyses. Age persisted as the lone independent predictor of LOS in the multivariate model $\left(\mathrm{P}<0.05, \mathrm{R}^{2}=0.076\right)$, and age and CAD were both independent predictors of cost $\left(P<0.05, R^{2}=0.109\right)$ in a stepwise multiple linear regression analysis. Neither sex nor nonsteroidal anti-inflammatory drug use predicted LOS or cost. CONCLUSIONS: Admissions for acute LGIH are associated with significant resource utilization, particularly among elderly patients with CAD.

Key Words: Cost; Gastrointestinal hemorrhage; Length of stay; Resource utilization

\section{Utilisation des ressources pour l'hémorragie digestive basse aiguë : L'Ontario GI Bleed Study}

OBJECTIFS : L'hémorragie digestive basse aiguë (HDBA) est une indication fréquente de l'hospitalisation. Par contre, peu d'études ont été publiées sur l'utilisation des ressources en soins de santé qui y sont associées. L'utilisation des ressources, la durée du séjour et les coûts médicaux directs ont été caractérisés auprès d'une cohorte de patients admis pour HDBA non maligne dans des centres de santé ontariens.

MÉTHODES : Les admissions consécutives pour HDBA ont été identifiées dans quatre hôpitaux ontariens. Les profils d'utilisation des ressources, la durée des séjours et les estimations des coûts médicaux directs ont été compilés par le biais d'un examen détaillé des dossiers et par l'adaptation

suite à la page suivante

Department of Medicine (Division of Gastroenterology), McMaster University, Hamilton, Ontario

Correspondence: Dr John K Marshall, Division of Gastroenterology (4W8), McMaster University Medical Centre, 1200 Main Street West,

Hamilton, Ontario L8N 325. Telephone 905-521-2100 ext 76782, fax 905-521-4958, e-mail marshll@mcmaster.ca

Received for publication January 14, 2002. Accepted August 1, 2002 
d'une base de données administratives. Tous les centres participaient à l'Ontario Case Cost Project. Des modèles de régression linéaires des données log-transformées ont été construits pour identifier les variables démographiques pouvant prédire la durée du séjour et les coûts des cas. RÉSULTATS : Chez les 124 patients inscrits (moyenne d'âge 58,8 ans), le coût moyen par cas a été de 4832 \$ (É.-T. : 7187 \$) pour une hospitalisation de 7,5 jours (É.-T. : 12,0). La diverticulite a été la source de l'hémorragie la plus souvent identifiée $(34,6 \%)$, suivie des hémorroïdes $(13,7 \%)$ et de la colite ischémique $(9,7 \%)$. La vieillesse et la présence de comorbidités, plus précisément de coronaropathie, ont été associées à un séjour plus long et à un coût par cas plus élevé lors des analyses de régression univariées, alors que l'âge persistait à titre de facteur de prévisibilité indépendant du séjour hospitalier dans le modèle multivarié $\left(\mathrm{p}<0,05, \mathrm{R}^{2}=0,76\right)$ et l'âge et la coronaropathie ont tous deux été des facteurs de prévisibilité indépendants du coût $\left(\mathrm{p}<0,05, \mathrm{R}^{2}=0,109\right)$ dans le cadre d'une analyse de régression linéaire multiple par étapes. Ni le sexe ni le recours à des anti-inflammatoires non stéroïdiens n'ont semblé exercer une influence sur la durée du séjour ou sur le coût.

CONCLUSION : Les admissions pour HDBA ont été associées à une utilisation significative des ressources, particulièrement chez les patients âgés souffrant de coronaropathie.
$\mathrm{L}^{\mathrm{o}}$ ower gastrointestinal hemorrhage (LGIH) is a common indication for hospitalization worldwide. In the United States, the annual incidence of hospitalization is 21 to 27 per 100,000 population $(1,2)$, and in one report, LGIH accounted for $0.7 \%$ of total hospital discharges (3). Despite this illness burden, there are few published studies of associated resource utilization and medical costs. The Ontario GI Bleed Study was initiated to quantify hospital resource utilization, estimate direct medical case costs for gastrointestinal hemorrhage and identify their relationship with demographic variables. Similar analyses of acute nonvariceal upper gastrointestinal hemorrhage have been reported previously $(4,5)$.

\section{MATERIALS AND METHODS}

The study was conducted at four hospitals in Ontario. Sites 1 and 3 were teaching centres affiliated with Canadian medical schools, and sites 2 and 4 were community hospitals with no such associations. All sites were participants in the Ontario Case Cost Project (OCCP) (see below). The research ethics boards of each participating institution approved the study on the condition that individual centres would not be identified by name.

In Canada, health care is funded publicly and administered by provincial governments. Hospital global budgets in Ontario are negotiated annually with the provincial ministry of health, whereas physicians are reimbursed separately, largely on a fee-for-service basis.

Consecutive admissions for LGIH were identified at each site. The discharge records of all admissions during the fiscal years 1994/95 and 1995/96 were searched for the following International Classification of Diseases, ninth revision codes as a primary or secondary discharge diagnosis: 578.9 (gastrointestinal hemorrhage), 569.3 (hemorrhage from anus/rectum) and 578.1 (blood in stool). A manual chart review was then undertaken to confirm eligibility according to the following criteria: age 18 years or older at admission and LGIH as the primary indication for hospitalization. Patients were excluded for any of the following reasons: bleeding attributed to gastrointestinal malignancy; diagnosis of liver cirrhosis; or known bleeding diathesis (including therapeutic anticoagulation). These criteria were imposed to identify cases in which the management of bleeding was the principal issue throughout hospitalization. For patients with multiple admissions during the study period, only data from the first admission were used.

The following descriptive data were extracted for each patient: age at admission; sex; date and time of arrival and discharge; and use of nonsteroidal anti-inflammatory drugs (NSAIDs). Documentation of prespecified comorbid diagnoses (coronary artery disease [CAD], diabetes mellitus, hypertension, chronic obstructive pulmonary disease or asthma, congestive heart failure and dysrhythmias) was sought from medical admission and progress notes. The presumed primary source of bleeding was inferred from physician notes and discharge summaries. Time spent in the emergency department, medical ward, intensive care and stepdown units was tabulated to determine the wardspecific and total length of stay (LOS).

Resource utilization profiles for each patient were adapted from a hospital administrative database developed in collaboration with the OCCP. The OCCP was a joint initiative of the Ontario Ministry of Health and the Ontario Hospital Association, involving 16 hospitals (6). Each participating centre developed a detailed, itemized cost database indexed by individual patient encounter. Costing algorithms abided by the Guidelines for Management Information Systems in Canadian Health Care Facilities (7), which fully allocate hospital expenditures among standardized functional cost centres such as nursing, clinical laboratory, diagnostic imaging and pharmacy. Resources and services within functional cost centres are assigned variable costs for relevant material supplies, plus a workloadindexed proportion of fixed or overhead costs, such as labour, equipment and capital infrastructure (including depreciation). For each subject, a total case cost per admission was estimated by multiplying numbers of resource units by the total (ie, fixed plus variable) cost per resource unit. Direct nonmedical and indirect costs were not assessed, and physician reimbursement was not reflected in the estimates of total case costs.

The following demographic variables known to influence prevalence and/or outcome of LGIH were tested for their individual associations with case cost by linear regression: age at admission, sex, NSAID use and the presence of prespecified comorbid illnesses (2,8-12). Univariate and unforced, stepwise multiple regression 
TABLE 1 Characteristics of 124 patients consecutively enrolled at four Ontario hospitals for lower gastrointestinal hemorrhage

\begin{tabular}{|c|c|c|c|c|c|}
\hline & \multicolumn{2}{|c|}{ Academic } & \multicolumn{2}{|c|}{ Community } & \multirow[b]{2}{*}{ Total $(n=124)$} \\
\hline & Site $1(n=26)$ & Site $3(n=33)$ & Site 2 ( $n=32)$ & Site $4(n=33)$ & \\
\hline Mean age (years) & 60.0 & 56.1 & 52.1 & 67.1 & 58.8 \\
\hline Male sex (\%) & $15(57.7)$ & $18(54.5)$ & $10(31.3)$ & $17(51.5)$ & $60(48.4)$ \\
\hline NSAID use (\%) & $9(34.6)$ & $7(21.2)$ & $8(25.0)$ & $12(36.4)$ & $32(29.0)$ \\
\hline \multicolumn{6}{|l|}{ Comorbid illness (\%) } \\
\hline 0 & $13(50.0)$ & $28(84.8)$ & $25(78.1)$ & $23(69.7)$ & $89(71.8)$ \\
\hline 1 & $8(30.8)$ & $3(9.1)$ & $4(12.5)$ & 7 (21.2) & $22(17.7)$ \\
\hline 2 or more & $5(19.2)$ & $2(6.1)$ & $3(9.4)$ & $3(9.1)$ & $13(10.5)$ \\
\hline \multicolumn{6}{|l|}{ Bleeding source (\%) } \\
\hline Diverticular bleed & $8(30.8)$ & 7 (21.2) & $5(15.6)$ & $23(69.7)$ & $43(34.7)$ \\
\hline Hemorrhoids & $6(23.1)$ & $3(9.1)$ & 7 (21.9) & $1(3.0)$ & $17(13.7)$ \\
\hline Ischemic colitis & $3(11.5)$ & $1(3.0)$ & $4(12.5)$ & $4(12.1)$ & $12(9.7)$ \\
\hline Crohn's disease & $2(7.7)$ & $4(12.1)$ & $4(12.5)$ & $1(3.0)$ & $11(8.9)$ \\
\hline Polyposis & $3(11.5)$ & $3(9.1)$ & $3(9.4)$ & $1(3.0)$ & $10(8.1)$ \\
\hline Ulcerative colitis & $0(0.0)$ & $5(15.2)$ & $1(3.1)$ & $2(6.1)$ & $8(6.5)$ \\
\hline Angiodysplasia & $4(15.4)$ & $1(3.0)$ & $2(6.3)$ & $0(0.0)$ & $7(5.6)$ \\
\hline Infection & $0(0.0)$ & $0(0.0)$ & $4(12.5)$ & $0(0.0)$ & $4(3.2)$ \\
\hline Other & $0(0.0)$ & $6(18.2)$ & $2(0.1)$ & $0(0.0)$ & $8(6.2)$ \\
\hline Unknown & $0(0.0)$ & $3(9.1)$ & $0(0.0)$ & $1(3.0)$ & $4(3.2)$ \\
\hline
\end{tabular}

NSAID Nonsteroidal anti-inflammatory drug

models were constructed using the above variables to identify independent predictors of case cost.

Despite similar costing algorithms, it was anticipated that the costs assigned to individual resource units might differ among centres and add variation to the total estimated case costs. For this reason, LOS was used as a secondary, surrogate measure of resource utilization (13), and regression models using LOS as the dependent variable were also constructed. Logarithmic transformations of dependent variables (case cost and LOS) were undertaken to reduce skew, render distributions closer to normal and facilitate regression analysis.

All costs are reported in Canadian dollars $(\mathrm{CDN} \$ 1.00=$ US\$0.65), and were converted to year 2002 dollar equivalents using the health and personal care component of the Consumer Price Index for Canada.

Patient cohort

\section{RESULTS}

A total of 124 eligible patients admitted with LGIH were identified at the four sites (Table 1). Sixty patients $(48.8 \%)$ were male, and the average age was 58.8 years (SD 19.0). Thirty-six patients (29.0\%) were using NSAIDs at the time of admission. The majority, 89 patients $(71.8 \%)$, suffered from none of the prespecified comorbid illnesses.
The source of bleeding was identified as diverticular disease in 43 patients $(34.7 \%)$, hemorrhoids in 17 (13.7\%), ischemic colitis in $12(9.7 \%)$, Crohn's disease in $11(8.9 \%)$, polyposis in $10(8.1 \%)$, ulcerative colitis in eight $(6.5 \%)$, angiodysplasia in seven (5.6\%), infection in four $(3.2 \%)$, other sources in eight (3.2\%) and an unknown source in four $(3.2 \%)$ patients.

One patient $(0.8 \%)$ died. Three patients were transferred to other institutions. Resource utilization, LOS and case costs for the latter were not captured after transfer because the receiving centres were not participants in the OCCP. All of the remaining patients survived to discharge from hospital.

\section{RESOURCE UTILIZATION AND CASE COSTS}

Consumption of key resources specific to the management of LGIH is summarized in Table 2. A mean of 6.7 complete blood counts (SD 7.2) and 1.1 coagulation profiles (SD 2.2) were performed per patient. One hundred patients (80.6\%) underwent endoscopy, principally colonoscopy. Twelve patients $(9.7 \%)$ underwent surgery because of recurrent or persistent hemorrhage.

Overall, the mean LOS was 7.5 days (SD 12.0, median 5.0, interquartile range 3 to 7 ) (Table 2). Patients spent an average of 0.2 days in the emergency room (SD 0.4) and 0.5 days in the intensive care or stepdown units (SD 1.6). Of 
TABLE 2

Resource utilization and case costs per admission for 124 patients consecutively enrolled at four Ontario hospitals for lower gastrointestinal hemorrhage (values represent means)

\begin{tabular}{|c|c|c|c|}
\hline & $\begin{array}{c}\text { Academic } \\
\text { Sites 1, } 3 \\
(n=59)\end{array}$ & $\begin{array}{c}\text { Community } \\
\text { Sites 2, } 4 \\
(n=65)\end{array}$ & $\begin{array}{c}\text { Total } \\
(n=124)\end{array}$ \\
\hline \multicolumn{4}{|l|}{ Laboratory } \\
\hline $\mathrm{CBC}$ & 7.63 & 5.82 & 6.68 \\
\hline INR & 1.80 & 0.51 & 1.12 \\
\hline Blood transfusion & 1.73 & 1.55 & 1.64 \\
\hline \multicolumn{4}{|l|}{ Radiology } \\
\hline X-rays & 2.00 & 0.88 & 1.41 \\
\hline Barium enema & 0.15 & 0.18 & 0.17 \\
\hline Ultrasound & 0.27 & 0.09 & 0.18 \\
\hline Red blood cell scan & 0.15 & 0.14 & 0.15 \\
\hline Angiogram & 0.22 & 0.01 & 0.11 \\
\hline Abdominal CT & 0.12 & 0.01 & 0.06 \\
\hline \multicolumn{4}{|l|}{ Endoscopy } \\
\hline Colonoscopy & 0.80 & 0.57 & 0.68 \\
\hline Sigmoidoscopy & 0.20 & 0.40 & 0.31 \\
\hline Gastroscopy & 0.27 & 0.28 & 0.27 \\
\hline Surgery & 0.15 & 0.04 & 0.10 \\
\hline Total LOS (days) & 9.93 & 5.32 & 7.52 \\
\hline Total case cost $(\mathrm{CDN} \$)$ & 6,775 & 3,068 & 4,832 \\
\hline
\end{tabular}

CBC Complete blood count; CT Computed tomography; INR International normalized ratio; LOS Length of stay; $X$-rays Combined chest and abdominal films

the 15 patients who spent time in an intensive care or stepdown unit, the average stay was 3.9 days (SD 3.0). The mean direct medical cost was $\mathrm{C} \$ 4,832$ per admission (SD $\$ 7,186$, median $\$ 2,128$, interquartile range $\$ 1,354$ to $\$ 3,957)$.

\section{SUBGROUP ANALYSES}

The mean case costs and LOS in selected subgroups are presented in Table 3. Patients aged 75 years and older $(n=32)$ incurred mean costs of $\$ 7,167$ for 11.8 days in hospital compared with mean costs of $\$ 4,020$ for 6.0 days in hospital for those under age 75 years $(n=92)$.

Patients with none of the prespecified comorbid illnesses had a mean case cost of $\$ 4,229$ compared with $\$ 5,796$ and $\$ 7,869$ for patients with one and two or more comorbid illnesses, respectively. The mean case cost for patients with CAD $(n=14)$ was $\$ 9,402$ for 9.57 days in hospital.

Data for the 43 patients with diverticular disease as the primary source of bleeding were analyzed separately (Table 3). Compared with patients with nondiverticular bleeds, these patients were older (73.3 versus 52.2 years, $\mathrm{P}<0.05$ ), more likely to use NSAIDs (53.5\% versus $16.0 \%, \mathrm{P}<0.05$ )
TABLE 3

Subgroup analysis of direct medical case costs and length of stay

\begin{tabular}{lccc}
\hline & $\begin{array}{c}\text { Case costs } \\
\text { (mean } \\
\text { 2002 CDN\$) }\end{array}$ & $\begin{array}{c}\text { Length } \\
\text { of stay } \\
\text { (days) }\end{array}$ & $\mathbf{n}$ \\
\hline Age (years) & & & \\
$20-39$ & 4,227 & 6.1 & 26 \\
$40-59$ & 3,155 & 6.0 & 27 \\
$60-74$ & 4,880 & 6.0 & 39 \\
$75-86$ & 7,167 & 11.8 & 32 \\
NSAID use & & & \\
Yes & 4,745 & 7.7 & 36 \\
No & 4,867 & 7.4 & 88 \\
Comorbid illness & & & \\
0 & 4,229 & 7.4 & 89 \\
1 & 5,796 & 7.4 & 22 \\
2 or more & 7,329 & 8.2 & 13 \\
Bleeding source & & 6.7 & 43 \\
Diverticular & 3,965 & 7.9 & 81 \\
Other & 5,292 & & \\
\hline NSAID Nonsteroidal anti-inflammatory drug & & \\
\hline
\end{tabular}

and more likely to suffer at least one comorbid illness (44.2\% versus $19.8 \%, \mathrm{P}<0.05)$. However, their average case costs and LOS were marginally lower at $\$ 3,965$ versus $\$ 5,292(\mathrm{P}=0.45)$ and 6.7 days versus 7.93 days $(\mathrm{P}=0.33)$, respectively.

Mean case costs and LOS were higher for patients admitted to academic centres $(\$ 6,775$ for 9.9 days, $n=59)$ than community centres $(\$ 3,068$ for 5.3 days, $n=65, P<0.05)$ despite similar age, sex, NSAID use and comorbid illness (Table 2). Colonoscopy was performed more often in the academic centres $(0.80$ versus 0.57 per patient, $\mathrm{P}<0.05)$, whereas more patients underwent sigmoidoscopies in community centres $(0.40$ versus 0.20 per patient, $\mathrm{P}<0.05)$. However, this study was neither intended nor designed a priori to test for differences among individual participating centres.

\section{LINEAR REGRESSION MODELS}

Because case costs and LOS were not normally distributed, a logarithmic transformation of both dependent variables was performed before all regression analyses. This reduced the skew from 2.88 to 0.17 for case costs and from 6.71 to 0.43 for LOS.

In univariate linear regression, age and number of comorbid illnesses were associated with both prolonged LOS and increased case cost $(\mathrm{P}<0.05)$. When individual comorbid illnesses were tested for their association with LOS and cost, only CAD showed a significant association 
$(\mathrm{P}<0.05)$. Neither sex nor NSAID use at admission predicted LOS or cost.

In a stepwise, multiple linear regression model, age persisted as the lone predictor of LOS in the multivariate model $\left(\mathrm{P}<0.05, \mathrm{R}^{2}=0.076\right)$; however, age and $\mathrm{CAD}$ were copredictors of cost $\left(\mathrm{P}<0.05, \mathrm{R}^{2}=0.109\right)$ using logtransformed data. A scatterplot depicting the relationship between age, history of CAD and case cost is shown in Figure 1.

When the population was restricted to those with diverticular hemorrhage, regression models showed only age to be an independent predictor of cost $\left(R^{2}=0.109\right)$ and LOS $\left(\mathrm{R}^{2}=0.119\right)$.

\section{DISCUSSION}

The present study characterized a consecutive cohort of patients admitted with acute LGIH and managed in a Canadian health care setting. The average direct medical case cost was $\$ 4,832$ for 7.5 days in hospital, and was positively correlated with age and history of CAD. Patients over age 75 years with CAD incurred an average case cost of $\$ 6,713$ for 8.8 days in hospital.

In the present study, older age and a history of CAD were predictors of higher direct medical case costs for LGIH. These results are congruent with other evidence that age influences resource utilization $(4,5)$ and outcome $(14,15)$ in upper gastrointestinal hemorrhage and other medical illnesses (16-18). Comorbidity, specifically CAD, has also been correlated with a poorer outcome and rebleeding in upper gastrointestinal hemorrhage $(15,19)$. In lower gastrointestinal bleeding after polypectomy, age has been associated with higher transfusion requirements (20). Comorbidity (one component of a composite risk score) has been shown to predict the outcome of LGIH (9).

Diverticular disease was the most common source of bleeding in the present study (34.7\% of patients). Costs and LOS in this group were slightly lower than those of patients with nondiverticular bleeds, despite increased age and greater comorbidity. This may reflect, in part, the selflimited nature of most diverticular bleeds (21).

NSAIDs have been identified as a risk factor for LGIH $(10,12,22)$, particularly in patients with diverticular disease (11). In our population, NSAID use was more prevalent among patients with diverticular bleeding (53\%) than among those with nondiverticular sources (16\%). However, NSAID use was not associated with increased resource utilization. Similarly, rates of hospitalization for LGIH were higher among men than among women (1), but our analysis did not identify sex as a predictor of resource utilization once bleeding occurs.

Hospital teaching status and attending physician specialty have been shown to affect LOS and case costs in upper gastrointestinal hemorrhage $(23,24)$; however, there are no equivalent data for LGIH. In our study, mean case costs and LOS were higher among patients admitted to academic centres than to those admitted to community centres, despite ostensibly similar patient profiles at admission.

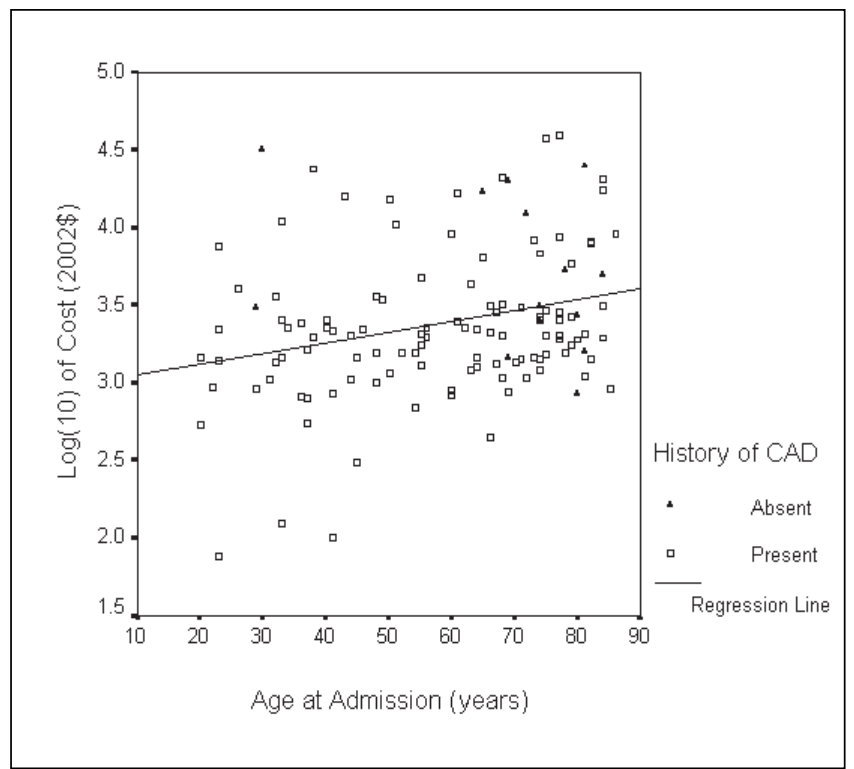

Figure 1) Scatter plot with regression line of log-transformed total direct medical case cost per admission versus patient age and history of coronary artery disease (CAD)

However, these data must be interpreted with extreme caution. Patients were not matched a priori for diagnosis or illness severity, and variations in resource use may reflect inherent differences in patient acuity and case-mix. Furthermore, costs and LOS were underestimated for the three subjects transferred to other centres. Accordingly, our data require careful, prospective validation.

To our knowledge, there are no similar published estimates of direct medical case costs for LGIH with which to compare our findings. The mean case cost for management of bleeding peptic ulcer disease in a similar Canadian study was $\$ 2,953$ for 5.7 days in hospital (1997 Canadian dollars) (5). Although health care standards in Canada and the United States are similar (25-27), our results may not be generalizable to practice settings outside of Ontario. The transfer of economic evaluations of health care technologies across jurisdictions is limited by differences in practice patterns, population profiles and reimbursement structures (28). Thus, decision makers in such settings must still look to validate our results with locally relevant data.

Better understanding and recognition of differences in resource utilization among demographic subgroups is needed to target care pathways and/or practice guidelines for the management of LGIH. Strategies that avoid, streamline or shorten admissions may yield the greatest savings when applied to resource-intensive subgroups, such as the elderly. For example, rapid colonoscopy protocols for LGIH have been found to achieve substantial cost savings $(29,30)$, and early discharge algorithms for upper gastrointestinal hemorrhage are receiving increased attention (19). While our data are useful to protocol development, additional information from larger populations and/or bleed registries is required. 
In summary, we have shown that admissions for LGIH consume substantial health care resources, particularly among elderly patients with CAD. In an era of constrained health care resources, careful examination of factors that influence resource utilization and case costs is needed.

ACKNOWLEDGEMENTS: Unrestricted financial support for this study was provided by Searle Canada (Oakville, Ontario).

\section{REFERENCES}

1. Longstreth GF. Epidemiology and outcome of patients hospitalized with acute lower gastrointestinal hemorrhage: a population-based study. Am J Gastroenterol 1997;92:419-24.

2. Bramley PN, Masson JW, McKnight G, et al. The role of an openaccess bleeding unit in the management of colonic haemorrhage. A 2-year prospective study. Scand J Gastroenterol 1996;31:764-9.

3. Vernava AM III, Longo WE, Virgo KS, et al. A nationwide study of the incidence and etiology of lower gastrointestinal bleeding. Surg Res Commun 1996;18:113-20.

4. Marshall JK, Collins SM, Gafni A. Prediction of resource utilization and case cost for acute nonvariceal upper gastrointestinal hemorrhage at a Canadian community hospital. Am J Gastroenterol 1999;94:1841-6.

5. Marshall JK, Collins SM, Gafni A. Demographic predictors of resource utilization for bleeding peptic ulcer disease: the Ontario GI Bleed Study. J Clin Gastroenterol 1999;29:165-70.

6. Ontario Case Cost Project: Ontario guide to case costing (Version 1.1). Toronto: Ontario Ministry of Health and Ontario Hospital Association, 1995.

7. Guidelines for Management Information Systems in Canadian Health Care Facilities. Ottawa: Canadian Institute for Health Information, 1985.

8. Farrell JJ, Friedman LS. Gastrointestinal bleeding in older people. Gastroenterol Clin North Am 2000;29:1-36.

9. Kollef MH, O'Brien JD, Zuckerman GR, et al. BLEED: a classification tool to predict outcomes in patients with acute upper and lower gastrointestinal hemorrhage. Crit Care Med 1997;25:1125-32.

10. Holt S, Rigoglioso V, Sidhu M, et al. Nonsteroidal antiinflammatory drugs and lower gastrointestinal bleeding. Dig Dis Sci 1993;38:1619-23.

11. Foutch PG. Diverticular bleeding: are nonsteroidal anti-inflammatory drugs risk factors for hemorrhage and can colonoscopy predict outcome for patients? Am J Gastroenterol 1995;90:1779-84.

12. Wilcox CM, Alexander LN, Cotsonis GA, et al. Nonsteroidal antiinflammatory drugs are associated with both upper and lower gastrointestinal bleeding. Dig Dis Sci 1997;42:990-7.
13. Maetzel A, Ferraz MB, Bombardier C. The cost-effectiveness of misoprostol in preventing serious gastrointestinal events associated with the use of nonsteroidal antiinflammatory drugs. Arthritis Rheum 1998;41:16-25.

14. Clason AE, Macleod DA, Elton RA. Clinical factors in the prediction of further haemorrhage or mortality in acute upper gastrointestinal haemorrhage. Br J Surg 1986;73:985-7.

15. Rockall TA, Logan RF, Devlin HB, et al. Risk assessment after acute upper gastrointestinal haemorrhage. Gut 1996;38:316-21.

16. Rosenthal GE, Landefeld CS. Do older Medicare patients cost hospitals more? Evidence from an academic medical center. Arch Intern Med 1993;153:89-96.

17. Rosen AB, Humphries JO, Muhlbaier LH, et al. Effect of clinical factors on length of stay after coronary artery bypass surgery: results of the cooperative cardiovascular project. Am Heart J 1999;138:69-77.

18. Munoz E, Rosner F, Chalfin D, et al. Financial risk and hospital cost for elderly patients. Age- and non-age-stratified medical diagnosis related groups. Arch Intern Med 1988;148:909-12.

19. Hussain H, Lapin S, Cappell MS. Clinical scoring systems for determining the prognosis of gastrointestinal bleeding. Gastroenterol Clin North Am 2000;29:445-64.

20. Sorbi D, Norton I, Conio M, et al. Postpolypectomy lower GI bleeding: descriptive analysis. Gastrointest Endosc 2000;51:690-6.

21. Buchman TG, Bulkley GB. Current management of patients with lower gastrointestinal bleeding. Surg Clin North Am 1987;67:651-64.

22. Peura DA, Lanza FL, Gostout CJ, et al. The American College of Gastroenterology Bleeding Registry: preliminary findings. Am J Gastroenterol 1997;92:924-8.

23. Quirk DM, Barry MJ, Aserkoff B, et al. Physician specialty and variations in the cost of treating patients with acute upper gastrointestinal bleeding. Gastroenterology 1997;113:1443-8.

24. Cooper GS, Chak A, Harper DL, et al. Care of patients with upper gastrointestinal hemorrhage in academic medical centers: a community-based comparison. Gastroenterology 1996;111:385-90.

25. Rouleau JL, Moye LA, Pfeffer MA, et al. A comparison of management patterns after acute myocardial infarction in Canada and the United States. The SAVE investigators. N Engl J Med 1993;328:779-84.

26. Redelmeier DA, Fuchs VR. Hospital expenditures in the United States and Canada. N Engl J Med 1993;328:772-8.

27. Fuchs VR, Hahn JS. How does Canada do it? A comparison of expenditures for physicians' services in the United States and Canada. N Engl J Med 1990;323:884-90.

28. Drummond MF, Bloom BS, Carrin G, et al. Issues in the crossnational assessment of health technology. Int J Technol Assess Health Care 1992;8:671-82.

29. Richter JM, Christensen MR, Kaplan LM, et al. Effectiveness of current technology in the diagnosis and management of lower gastrointestinal hemorrhage. Gastrointest Endosc 1995;41:93-8.

30. Jensen DM, Machicado GA. Colonoscopy for diagnosis and treatment of severe lower gastrointestinal bleeding. Routine outcomes and cost analysis. Gastrointest Endosc Clin North Am 1997;7:477-98. 


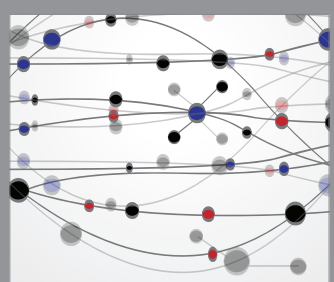

The Scientific World Journal
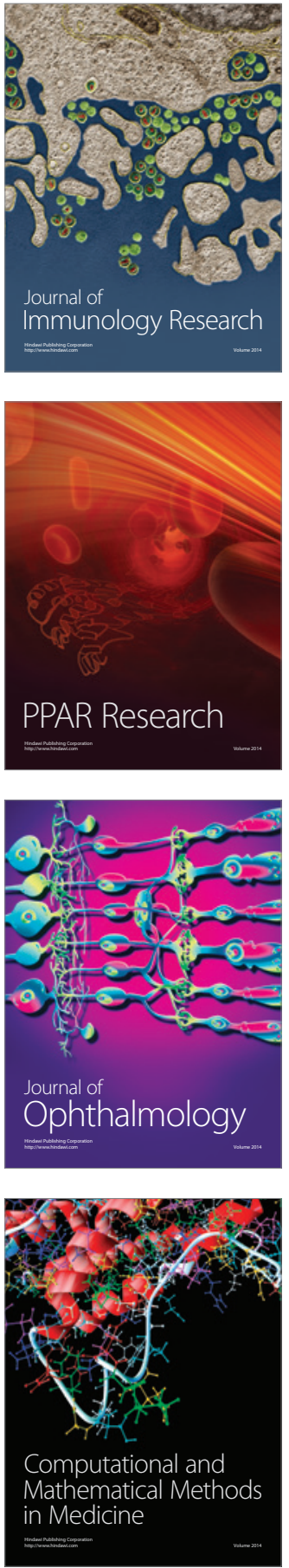

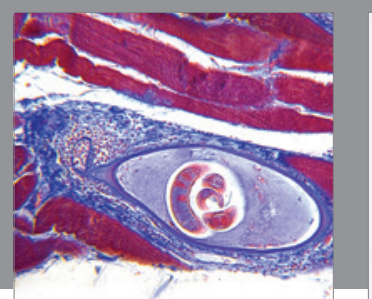

Gastroenterology Research and Practice

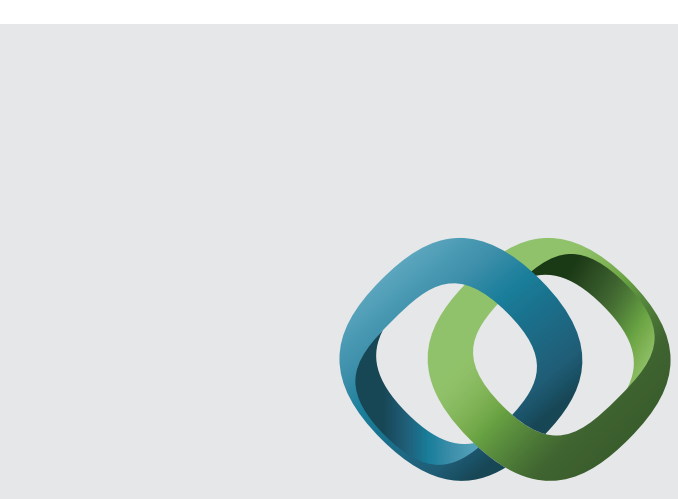

\section{Hindawi}

Submit your manuscripts at

http://www.hindawi.com
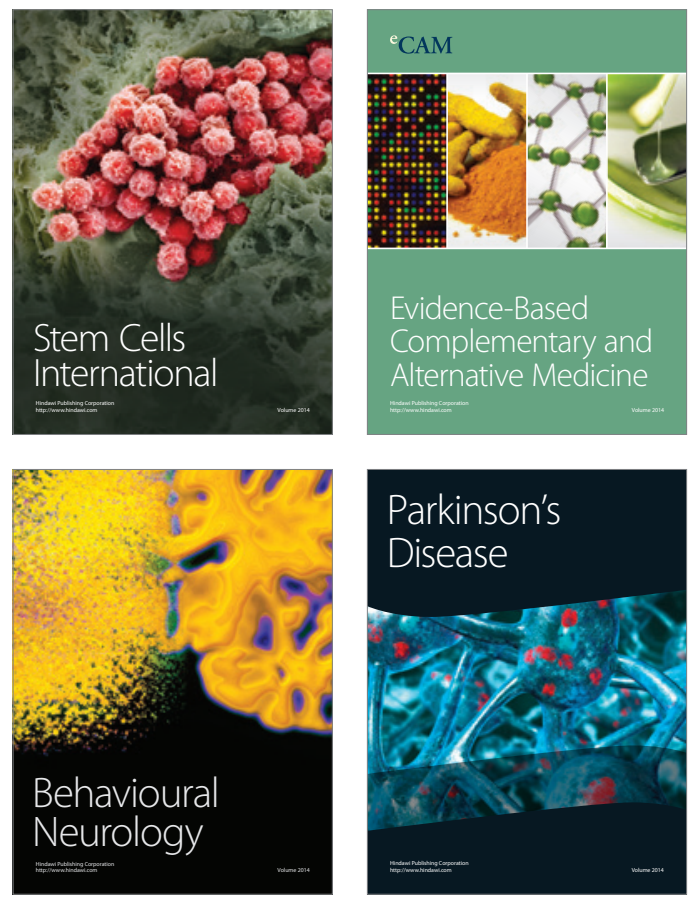
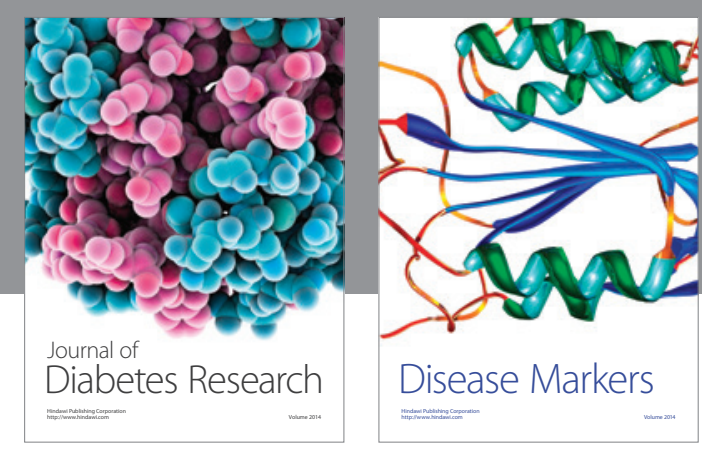

Disease Markers
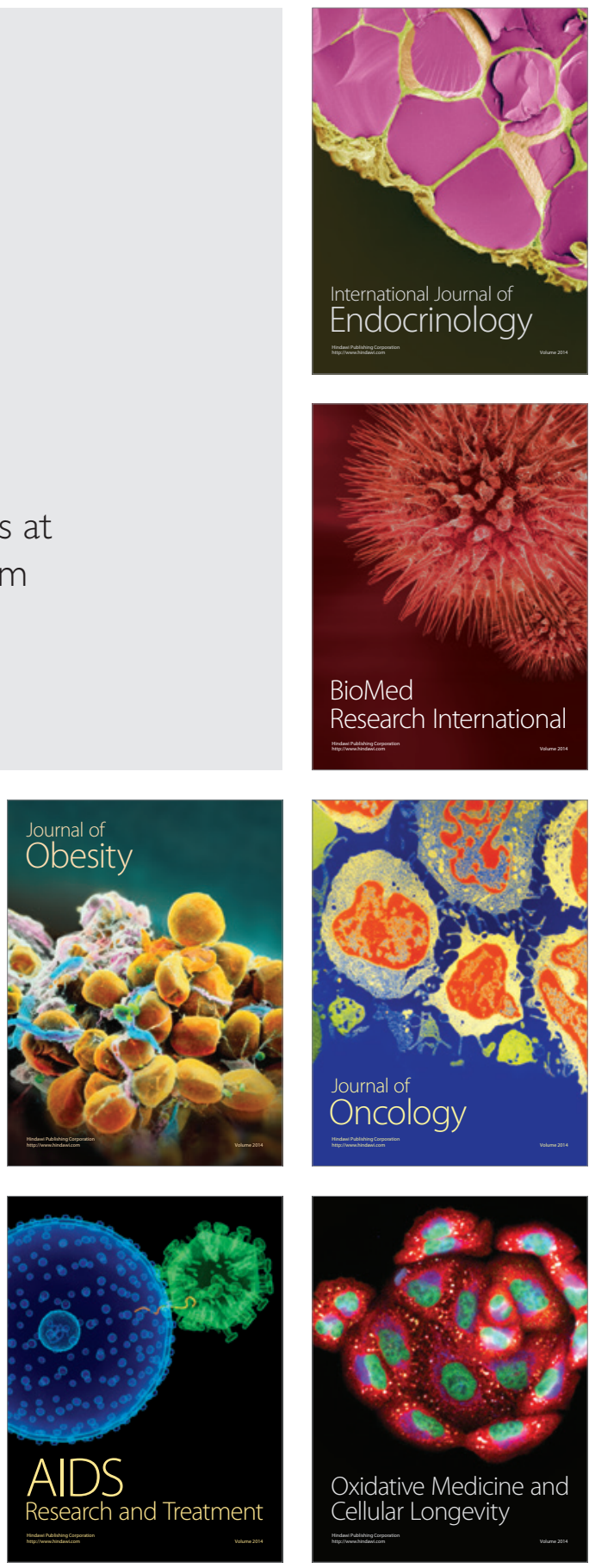